\title{
Bridging the Gap between Theory and Practice by the Use of Iterative Processes
}

\author{
Mona Holmqvist Olander $^{1} \&$ Constanta Olteanu ${ }^{2}$ \\ ${ }^{1}$ Department of Pedagogical Curricular and professional Studies, University of Gothenburg, Sweden \\ ${ }^{2}$ Department of Computer Science, Physics and Mathematics, Linnaeus University, Sweden \\ Correspondance: Mona Holmqvist Olander, Department of Pedagogical Curricular and professional Studies, \\ University of Gothenburg, Box 300, SE 40530 Gothenburg, Sweden. Tel: 64-31-786-2468. E-mail: \\ mona.holmqvist@gu.se
}

Received: November 9, 2012

Accepted: November 21, $2012 \quad$ Online Published: February 22, 2013

doi:10.5539/jel.v2n1p230

URL: http://dx.doi.org/10.5539/jel.v2n1p230

\begin{abstract}
The aim of this study is to study learning the positional ten base notation by the increase of students' test scores during the learning study process. Five teachers, one researcher and 53 students participated. Three research lessons in three different groups of students were conducted. The improvement in the third lesson (C) correlates with the more developed theoretical based assumptions the design is made, which resulted in a pattern of variation that stronger pointed out the aspect needed to discern to understand the object of learning in a new and more developed way. The differences in the third research lesson (C) was significant** $p=0.005$ while the differences in research lessons A and B were not significant.
\end{abstract}

Keywords: base 10 positional notation, compulsory school instruction, action research, learning study, teacher development

\section{Introduction}

\subsection{Teachers' Professional Development}

Research on teachers' professional development usually aims to support meaningful and sustainable shifts in practice, which Butler, Novak Lauscher, Jarvis-Selinger \& Beckingham (2004) claim requires analytical theories on learning. Such shifts can be made by the use of models such as the iterative process developed by Butler et al. (2004). The model includes concrete activities and access to mentors during a period of two years. Furthermore, the professional development usually aims to have some kind of impact on student outcomes. In a study on the impact of school leadership on pupil outcomes, one of the perceived challenges found is to "personalize the learning experience of the students" (Day, Sammons, Hopkins, Harris, Leithwood, Gu, Brown, Ahtaridou \& Kington, 2009, p. 193). This requires certain knowledge about what is possible to be aware of in a learning situation, and it is hard to see what students are learning. Nuthall (2004) says:

I have already made the point that teachers cannot be aware of critical elements in the teaching-learning process in their own classrooms unless they already have a clear understanding of what to look for and have additional ways of observing or recording the experiences of individual students. Working on their own, teachers can only see the classroom through their own eyes and can only occasionally see whatstudents are learning. (Ibid, p. 13)

$\mathrm{He}$ argues teachers only see what their culture finds significant, and this makes it hard to transform different cultural models (such as lesson study) from one culture to another, as some of the parts will not be discerned and thus missed in the transformation. Nuthall argues for analysis of learning in the classroom containing both assessments of the students' learning (as a difference between what they know before and after intervention) and observations of the learning situation. This is also highlighted by Morris and Hiebert (2011) who argue for "small tests for small changes" (Ibid, p. 6) instead of few and greater assessments. The argument is that changes more likely happen by making small changes in the classroom every now and then, rather than making one extensive change. They also claim useful instructions should be "testable and improvable" (Ibid, p. 9). One main feature for useful instruction is found to be the teachers' cooperation and teamwork while they try to solve the same problem. Holmqvist (2011),Olteanu and Olteanu (2010) have focused on teachers' professional development in relation to the students' learning outcomes using different models to achieve sustainable shifts in 
practice. In this article the result from one new study is presented. However, we start with presenting three previous learning studies. The model is based on action research, and the teachers are co-researchers in the iterative processes. The studied objects are formulated by the teachers and aim to capture what it takes to learn a specified phenomenon (Holmqvist, Gustavsson \& Wernberg, 2007). This is the joint problem to solve. A learning study relies on a theoretical framework about learning. This means that a learning study does not focus on the design of the lesson; it focuses rather on what it takes to learn the content and in what way the features of the content are varied to make the pupils discern all needed parts. Thus the design of the instruction is subordinated, and the output is not only increased learning outcomes for the students but also teachers' gaining of a tool to analyze learning in the classroom.

\subsection{Learning Study as an Iterative Process}

In the learning studies presented, variation theory is used as a theoretical framework (Marton \& Booth, 1997; Runesson 1999; Holmqvist, Gustavsson \& Wernberg 2008). Learning study has been found to improve teachers' professional development as well as the students' outcomes. But the results show it is not only the iterative process or the teachers' knowledge that makes the pupils learn more, although they promote learning possibilities.

The mathematical content that is in focus for this study is to experience the base 10 positional notation. Results from major studies indicated that decimals create great confusion for many students (e.g., Brown 1981; Hiebert \& Wearne 1985; Wearne \& Kouba 2000; Resnick et al. 1989; Steinle \& Stacey 1998, 2001, 2002, 2003). Some of the difficulties reported were:

- $\quad$ students treat decimals as whole numbers

- $\quad$ students have difficulty recognizing that a decimal number such as 0.530 is both 5 tenths, 3 hundredths, 0 thousandths, as well as 530 thousandths

- $\quad$ a longer decimal is larger than a shorter decimal

- $\quad$ students interpret the decimal as two whole numbers separated by a marker

- the zeros after the decimal point are likewise disregarded (6.3 and 6.03 would be seen as the same number)

The description of patterns of interpreting decimal notation above is extensive, but not comprehensive. For example, there further combinations of these patterns are possible. Many of the difficulties students have with decimal numbers stem from the fact that decimals are primarily taught as an extension of the place-value system. Students use the place-value column names to decide on the size of the decimals. They know that one tenth is larger than one hundredth and they incorrectly generalise that any number of tenths is greater than any number of hundredths. The decimal point is a special symbol that separates the position of the whole-number units on the left from the position of the fractional units on the right. The value to the right of the decimal point is $1 / 10$, which is the value of that place; the value two places to the right of the decimal point is $1 / 100$, which is the value of that place; and so on.

The results of three previous learning studies in the subjects Mathematics, English as second language and Literacy show how the teachers' understanding of how to use contrasts when presenting the object of learning resulted in significantly better learning outcomes by the pupils (Holmqvist, 2011). The main question in this study is - in what way can the teachers' and pupils' improved knowledge be related to the iterative processes used in the learning study-model? And as there are differences between the results from different groups of students - what features of the iterative process seem to be of significance for the differences? The hypothesis is that it takes more than an iterative process to make those changes, but the iterative process might be an important tool to use when searching for features needed to develop teachers' learning.

\subsection{Action Research}

Coulter (2002) claims education and action in fact get little attention in educational action research. Instead there is a strong focus on the relation between theory and practice. However, there is no clear connection between good practice and application on theory. Coulter claims it takes more than theoretical knowledge and experience to create good practice. Knowing what to do might make the teachers talk in an initiated way about their practice, but this does not necessarily mean there have been any changes in it.

Deciding what counts as good practice - understood as praxis - involves more than the application of theory or the exercise of skill. Determining what is the right thing to do in the right way at the right time - and actually doing it - involves a particular kind of judgment: phronesis, a term variously translated into English as 
“prudence" (Betner, 1983), "practical wisdom" (Reeve, 1992) and "practical judgment" (Steinberger, 1993)...] Teachers with phronesis must not only know what to do: they must do it (Coulter, 2002, p. 191).

Analyzing results from an educational action research project should be based on other data than interviews, observations and field-notes only, to capture what kind of changes actually occurred. Otherwise the teachers' way of talking about their changes or development in practice, the participants' enthusiasm noted by the observers and the expectations they all have on what they will achieve might guide the results in a much more positive direction than what is reasonable. Even if the teachers have both theoretical knowledge and are experienced, it does not mean they are able to use their abilities in a way that improves practice. Herr and Andersson (2005) present different kinds of approach in action research, and this study also takes departure in what is called technical action research, as empirical data from classrooms are used to describe the results. The researchers act as agents of change to improve the teaching situation (Wells, 2009). Wells has also described an educational action research project in which video-recorded observations were viewed together with the teachers to evaluate and improve their learning and teaching. The use of collaborative analyzes of video-recording is one of the steps in a learning study. The study described in this article is based on a strong interest to make the implicit features in practice explicit to improve practice. This means the result is not only based on analyses of data from the participating actors where they express statements of changes or developments. Analysis of assessment in the classroom is made based on two measurements; pre- and post-tests taken by the students and the video-recording. Results from previous studies have shown how difficult it is for the teachers to assess learning situations. They often assess them as more developing than the learning outcomes indicate or vice versa. By contrasting their expressed assessments of learning with data on the students' knowledge, a learning gap has been found (Holmqvist, Brante \& Tullgren, 2012; Olteanu, 2012). The departure in this article is that a reliable result about improved educational practice should include more than verbally expressed feedback from the participators, as the main aim is to improve learning, not thoughts or experiences of learning.

\section{Method}

Learning study (Holmqvist, 2011) is a theoretically based lesson study (Lewis 2002 and 2009, Yoshida \& Fernandez, 2004), where cycles are used to develop knowledge about what it takes to learn in different subject matters. Lewis (2009) has placed the lesson study model in the field of educational action research. She claims lesson study can support improvement of teacher and student learning. In the learning study model, the same lesson content is handled in different ways and in different groups of students. The model takes its departure in real problems experienced in the classrooms, and Elliott (2009) argues that the results of educational action research need to be discussed in terms of understandings and insights generated instead of descriptions and justifications of action research. He also emphasizes the development of theoretical knowledge during the research. The learning study model is flexible and should be adapted to the object of learning, which means it can consist of one single lesson per group (compared with other single lessons in other groups) or several lessons per group (compared to several lessons in other groups). However, the cyclic process is important because the results of the design of the first lesson are used to further improve the lesson design to develop an increased learning outcome. The model consists of an iterative process where the design of the first lesson is based on the results of the screening and the studies in subject didactics. The second lesson, in a new group of students, is revised based on the learning outcome, i.e. the assessed knowledge in the pre-test compared with the assessed knowledge in the post-test. Thus it is possible to describe what seem to have been understood by the students and what still seems to be hard for them to gain knowledge about. This will be repeated one more time, which means the Learning Study Cycle consists of at least three research lessons. The iterative process gives the teachers possibilities to gain knowledge about both the students' learning, learning about the subject and learning about the instruction's effect on learning. The process also includes video observations where the teachers study their own and their colleagues' teaching and the interaction in the classroom. However, the main aim in a learning study is to find out how the object of learning is handled in a classroom situation and what the students seem to discern of it. As mentioned above, learning study is a theory-based model, and the theory used so far is variation theory (Marton \& Booth, 1997, Holmqvist, Gustavsson \& Wernberg, 2008). Variation theory is based on the assumptions that discernment, simultaneity and variation are all required in a learning situation. You have to discern the phenomenon you are supposed to learn about, and the discernment is possible because of simultaneous awareness of varying aspects. When you decide if a person is tall or short requires the simultaneous awareness of varying heights; if everyone were exactly the same size, height would not be of importance and not necessarily discerned. The theoretical framework is used to design the instruction, and the teachers are introduced to the theory during the learning study cycle. This means their knowledge about the theoretical framework hopefully develops during the process and results in increased knowledge after each cycle. 
To simplify a rational expression is the subject in the three learning studies described here (Olteanu, 2012). The same objects of learning have been studied during three semesters. One learning study was implemented per semester (Learning Study A, B and C). In this study, three micro-cycles form a macro-learning study cycle (Learning Study A includes lessons A1 - A6). The participants in the study were two teachers, their pupils and researchers. The teachers were included in a team at a school for students aged 16-17 years. The numbers of participating students in the first learning study were 23 , in the second 18 and in the third study 24 . The first cycle starts with 3-5 meetings to discuss the theoretical framework (variation theory) and define the object of learning. At the outset of the learning study, a screening is made, which means the students' previous knowledge is assessed. Based on these results the tests and design of the first instruction are planned. Hence the lesson is jointly designed. Before the lesson the students take a pre-test, and after the lesson they take a post-test. This makes it possible to measure the development between the two assessments. The items in the test are designed to capture if the students have discerned the needed critical aspects (what it takes to learn the phenomenon) to understand the object of learning. The results of the first lesson are used to design the second lesson, which is implemented in a new group of students. This iterative process is repeated one more time (in total at least six lesson designs per learning study). The lessons are video-documented by two cameras and transcribed verbatim. The analysis of the instruction is made after each lesson and compared with the results of the tests taken by the pupils (pre-test, post-test and delayed post-test). Finally, all three learning study cycles (including six lessons each; $\mathrm{n}=18$ ) were analyzed and compared, as were the discussions during the meetings with teachers and researchers.

The focus in this article is not mainly the students' results; it is the effect of the iterative process that is highlighted. However, it seems that the cyclic process develops the teachers' abilities to design instruction in a way that makes the students understand the object of learning in a better way during the cycles. By discussing and analyzing both the lessons and the students' learning outcome with colleagues and researchers, the teachers seem to gain knowledge about what it takes to learn. In the three learning studies reported here, a pattern of variation of contrasts was used. The more able the teachers seem to be to handle contrasts to make the students learn, the more increased knowledge. In Holmqvist (2011), the outcomes of the learning studies have been hypothesis tested and there was significance differences between the controls and experimental (those offered the pattern of contrast in the research lesson) according to long-term student learning outcome. The research groups was mixed in three new groups, out of three classes, to prevent influence of the teaching afterwards. As the students returned to three different classes afterwards, they did not get the same treatment before or after the research lessons. The pre-test was taken before the lesson, the post-test direct after and the delayed post-test four weeks later. The results points out how the experimental group (students picked from three different classes) showed increased learning outcomes expressed in the test scores over time when exposed to the design where the pattern of contrast was used, no matter of teaching situation afterwards. Even if this is not an explicit finding supporting the hypothesis that iterative processes can be a tool to improve knowledge about how to design instruction, the results points at more developing learning situations showed in increased test-scores in some cycles (the experimental) than in others. The difference was significant due to a 3 × 2 × 3 ANOVA-test with three experiments (research lesson 1, 2 and 3 in each cycle A, B and C), two factors (one experimental and two controls), and three measurement occasions (pre-, post- and delayed post-test). The interest of the hypothesis-testing was to see if the experimental lesson (including the pattern of contrast) differed in some way based on scores in the tests. Decomposing it into trend contrasts showed a reliable quadratic trend, F $(1,159)=$ $11.43 ; \mathrm{p}=0.001$. The result gives a low support that the pattern of contrast generates long term learning outcomes. By that it is shown that it is not the iterativity as such that makes a difference; it seems that other aspects are crucial to develop increased learning, and former studies have shown different learning outcome despite the use of the same iterative model (learning study).

To further explain in what way the iterative model can be used to provide increased learning, a case study of how the teachers can gain knowledge about theoretical assumptions by the use of iteraty will be presented. However, the iteraty is also in this study used as a tool for teachers to capture aspects critical for designing powerful learning situations, a tool crafting refined knowledge about students' learning.

\subsection{Implementation}

The learning study aims to describe in what way students in grade seven experience the base 10 positional notation before and after three differently designed lessons in a learning study, each one given to one group of students (A, B and C). The aspects needed to discern when developing knowledge of the positional notation or "place-value notation" requires understanding the difference between figures' values and numbers. The students need to know that the same symbol (number) can be used to represent: 
1) different orders of magnitude such as "ones place" (3), "tens place" (30)

2) by the use of a radix point (decimal point) the same symbol can be used to represent fractions (the "tenths place, hundredths place" and so on $(33,33)$

3) quantity ( $3=$ i i i)

A total of 53 students participated in three different groups $(A=12, B=18, C=23)$ together with their five teachers and one researcher. The learning study started with two meetings with the teachers to present the theory upon which the study is based, variation theory, and to plan tests and lessons. The test was given to another class to see if the questions where suitable and if the time it takes to answer the questions was reasonable (10-15 minutes). The test included 8 questions, and 5 of those have sub queries, which resulted in 23 as a total score.

1) What numbers are there between 6 and 8 ?

2) Arrange the following numbers with the smallest first:

$\begin{array}{lllllr}\text { a. } & 1.1 & 1.4 & 1.9 & 1.05 & 1.3 \\ \text { b. } & 3.10 & 3.099 & 3.53 & 3.499 & 3.9\end{array}$

3) Write the following three numbers in these two number series:

a. $0.6 \quad 0.7 \quad 0.8$

b. $\quad 5.96 \quad 5.97 \quad 5.98$

4) How many tenths are there in these numbers?
a. 0,7
b. 1.7
c. 12.43

5) Numbers to solve;
a. $0.2+0.22$
b. $0.17+0.30$
c. $4.69+0.5$
d. $1+0.07$
6) Calculate;
a. $1+0.2$
b. $0.5 \times 0.5$
c. $0.6 \times 1$
d. $\quad 100 \times 0.2$
e. $0.7 \times 100$
f. $\quad 200 \times 0.8$
g. $\quad 0.3 \times 0.02$
h. $\quad 0.20 \times 0.3$

7) Write one hundred hundredths in so many different ways you can.

8) Write sixty-nine tenths in so many ways you can.

Chart 1. The test

\subsection{Pilot Study}

When the students solved two different kinds of arithmetical tasks in the pilot study (in a group of students not participating in the learning study but where the tests were validated) the challenge of how to use decimal terms in addition and decimal factors in multiplication requires knowledge about the base 10 positional notation system. The different ways of solving the two tasks affect their possibilities. In the multiplication tasks the knowledge of the positional notation is not critical for solving the task $0.5 \times 0.5$, as they can count the amount of decimals in the factors (two) and then put the decimal point two steps to the left (0.25). But the addition of the terms 0.2 and 0.22 is difficult to solve without knowledge about the positional notation. Otherwise they get the sum 0.24 
instead of 0.42 . Figures 2 and 3 show items 2 and 4 and common errors made by the students.

2. Arrange the following numbers with the smallest first:
A. 1.1
$1.05 \quad 1.3$
1.4
1.9

Common errors:
1.1
1.3
$1.4 \quad 1.05$
1.9

B. 3.10

3.099

3.53

3.499

3.9

Common errors:

$\begin{array}{lllll}3.9 & 3.10 & 3.53 & 3.099 & 3.499\end{array}$

Chart 2. Item 1 showing the difficulty to see the significance of placement in relation to value

4. How many tenths are there in the following expressions?

a. $0.3 \quad$ b. $1.7 \quad$ c. $\mathbf{1 2 . 4 3}$

$\begin{array}{lll}3 & 17 & 124.3\end{array}$

Common errors:

3

7

Chart 3. Item 2 showing the difficulty to separate value and position

\subsection{The Three Interventions}

The lessons differed in some respects among the three groups of students. The aim in all three lessons was to develop the students' knowledge about the positional notation system, in a way that makes them solve the items mentioned above in a more powerful way. To do so, the teachers in group A decided to point out the difference between ten and tenths and so on, making sure the students should not confuse them. Hence the positional notation system shown in Figure 4 was even more emphasized.

\begin{tabular}{lllllll}
\hline Thousands & Hundreds & Tens & Ones & Tenths & Hundreths & Thousandths \\
\hline 4 & 0 & 2 & 1 & 5 & 3 & 0 \\
\hline
\end{tabular}

Chart 4. The 10 base positional notation system

In lesson $\mathrm{A}$, the decimal point was not moved, even if they were discussing how it moved read out the number in different ways. To explain tens in lesson B, the decimal point was moved to digit 2 , and to explain thenths the decimal point was moved to the digit 5 .

In turn, this result in discerning the placement of the digits one by one, which makes the learner discern one single figure as tenths, which can explain the common mistake shown in Chart 3. The wholeness of the decimal number 4021.530 is not discerned. The number 4021.530 is separated into single figures, representing one position or value each (one digit each for ones, tens, tenths and so on). Thus no variation regarding either figures or decimal point was used in group A. The same number was used to explain the difference between the values, at the same time the digits differed, resulting in simultaneously variation in placement ant value at the same time. By that, what is critical to discern might have been difficult to focus. In B the decimal point varied, but the same schedule (Chart 4) was used. When the teacher talked about tenths, the decimal point was moved and put behind 5 to make the students discern the number instead of a single digit. This means even more variation was used, by shifting placement of the decimal-point. However, also in this example simultaneously variation was used. In the third lesson (C) the pattern of variation used made them discern the number 4021.530 as a whole no matter if they were talking about tens, ones or tenths (Chart 5). This design was evolved during the discussions with the teachers during the analysis of the video-recordings and the results of the assessments. The planned for decreased variation and only vary the placement of the decimal-point and not separating the digits from the 
whole number, as shown in Chart 5.

\begin{tabular}{ll}
\hline Thousands & 4.021530 \\
Hundreds & 40.21530 \\
Tens & 402.1530 \\
Ones & 4021.530 \\
Tenths & 40215.30 \\
Hundredths & 402153.0 \\
Thousandths & 4021530 \\
\hline
\end{tabular}

Chart 5. In lesson C, variation of decimal point, invariation of the mathematical expression 4021.53 without separation of the whole number into single digits was used as pattern of variation

The decimal number (4021.530) in group $\mathrm{C}$ can be discerned as a whole number (ones, tens, hundreds, ...) instead of pointing out one single figure as representing a value by itself. The design is based on the theoretical knowledge including what patterns of variation means when designing lessons. By varying the aspects needed to focus upon, and keeping the rest invariant, the aim to make the students understand the difference between value and placement expressed by the movements of the decimal-point in a whole number. By that they got the possibility to discern how the same number, by the change of position of the decimal-point, does not change value even if the decimal-point's placement varies. Instead they were asked to discern the same decimal number about ones (4021.530) simultaneously with hundreds (40.21530) and hundredths (402153.0) referring to the ones number. By contrasting them, the importance of the placement of the decimal point to explain tenths, hundredths and so on can be discerned as an important aspect in an invariant decimal number regarding other aspects. Hence the shift of perspective from each single digit's placement in the 10 base positional notation system to noticing the importance of the decimal point in a whole number facilitates the knowledge of how many tenths, hundredths and so on, an expression consists of.

\section{Results}

In a learning study, the result of the previous lesson represents the base for the improved design of the next lesson. In this study the pattern of variation and invariance between the designs makes the students discern the decimal number in different ways in groups A, B and C. As the difference between the pre- and post-test results was not significant in groups $\mathrm{A}$ and $\mathrm{B}$, the iterative process challenged the teachers to try harder to find a better way to redesign the lesson based on variation theory, and find another pattern to try out in the last group, which was successful (Table 1). The results have been analyzed due to percentage correct answers before and after each lesson. In lesson A the increase between the tests was +4 percentage units, in lesson B there was no increase, but in lesson $\mathrm{C}$ the increase was +14 percentage units.

Table 1. Correct answer in percentage in groups A, B and C

\begin{tabular}{llll}
\hline & A & B & C \\
\hline Pre-test & $27 \%$ & $51 \%$ & $50 \%$ \\
Post-test & $31 \%$ & $52 \%$ & $64 \%$ \\
Difference & +4 & +1 & +14 \\
\hline
\end{tabular}

The tests have also been analyzed to see how the means differs (Table 2). In lesson B, where the pattern of variation was rich on several varying aspects at the same time as the number (whole) was separated into single digits (parts) seem to have been problematic as the scores at the tests have not increased. The correlation between pre- and post-test is 1.00 . 
Table 2. Means and standard deviation for all groups (SPSS 20.0)

\begin{tabular}{llllll}
\hline & & Mean & N & St. Deviation & $\begin{array}{l}\text { Std. Error } \\
\text { Mean }\end{array}$ \\
\hline Pair 1 & A Post & 7.46 & 12 & 2.73 & 0.76 \\
& A Pre & 6.46 & 12 & 3.43 & 0.95 \\
Pair 2 & B Post & 11.32 & 18 & 4.51 & 1.03 \\
& B Pre & 11.53 & 18 & 4.50 & 1.03 \\
Pair 3 & C Post & 13.46 & 23 & 5.52 & 1.13 \\
& C Pre & 11.25 & 23 & 4.20 & 0.86 \\
\hline
\end{tabular}

The showed differences in mean support the results in percentage of correct answers. There is a difference in the first and third lesson, and the main difference is in the third lesson. If the assumptions behind variation theory is to be tested, the increased pattern of variation in lesson B (not to vary the critical aspect from an invariant background) and a more focused and decreased variation in lesson $\mathrm{C}$, the results should be highest in lesson $\mathrm{C}$ and lowest in lesson B.

Table 3. Differences in means for all groups

\begin{tabular}{llcll}
\hline Paired differences & & Mean & Std. Deviation & Std. Error Mean \\
\hline Pair 1 & APost - Apre & 1.00 & 3.29 & 0.91 \\
Pair 2 & BPost - Bpre & -0.21 & 1.93 & 0.44 \\
Pair 3 & CPost - Cpre & 2.21 & 3.48 & 0.71 \\
\hline
\end{tabular}

More than that, the results also show that the differences in test-scores between pre- and post-tests are significant only in the third lesson (C). The students seem to have changed their understanding, at least expressed in test-scores, in a significant way.

Table 4. Paired differences with a significant difference in research lesson $\mathrm{C}$ Paired Differences

\begin{tabular}{|c|c|c|c|c|c|c|c|c|c|}
\hline & & \multirow[b]{2}{*}{ Mean } & \multirow[b]{2}{*}{ Std. Deviation } & \multirow[b]{2}{*}{ Std. Error Mean } & \multicolumn{4}{|c|}{$\begin{array}{l}95 \% \text { confidence Interval } \\
\text { of the Difference }\end{array}$} & \multirow[b]{2}{*}{ Sig. (2-tailed) } \\
\hline & & & & & Lower & Upper & $\mathrm{t}$ & $\mathrm{dt}$ & \\
\hline Pair 1 & APost-APre & 1.00 & 3.29 & 0.91 & -0.99 & 2.99 & 1.095 & 12 & 0.295 \\
\hline Pair 2 & BPost-BPre & -0.21 & 1.93 & 0.44 & -1.14 & 0.72 & -0.475 & 18 & 0.640 \\
\hline Pair 3 & CPost-CPre & 2.21 & 3.48 & 0.71 & 0.74 & 3.68 & 3.112 & 23 & 0.005 \\
\hline
\end{tabular}

\section{Discussion}

Previous studies, as well as the study presented in this article, have shown that the students who participate in the interventions significantly improve their ways of answering written questions concerning the taught topic, here called the object of learning, if they are offered a pattern of variation where the critical aspect needed to develop new knowledge. It can always been argued that tests do not show the real learning outcome or knowledge, and we will not argue against this. However, as we use an iterative process, there is more than one lesson and the same tests are used in three different groups of students. If the increased scores are due to a learning situation itself, meaning that the students remember the calculation, this is an independent variable as all three groups are affected in the same way. It has also been claimed the differences could be due to the teacher's personality, results from other studies, where the same teacher have taught all classes, have shown the same kind of differences (Magnusson and Holmqvist, 2010). The iterative process, conducted in authentic practice and 
recognizing the contribution of the teachers both in planning, enactment and evaluation of the interventions, creates a structure which offers a more scientific way of developing learning in the classroom.

Furthermore, the aim in these studies is to draw conclusions grounded not only on statements from teachers, but also on test results from students and from in-depth analysis of design meetings and classroom interactions. This opens several 'black boxes', for example teachers' planning (intended object of learning), interactions during instruction (enacted object of learning) and students' learning outcome (lived object of learning). It can be claimed that the approach enhanced the possibilities to draw conclusions about important features of teacher development.

The studies also indicate that an iterative process in collaboration with teachers assessed in authentic practice has an impact on teacher development concerning the ability to design instruction. This is shown by the developed understanding required to create patterns of variation and find the aspects critical for learning. It is not the iterativty itself that is crucial either for the teachers' development or the students' increased knowledge. The iterative models are only tools used to capture aspects needed to be discerned to improve their instruction in a way that makes the students' learning outcome increase. Some kind of 'injection' (Elliot 2009) has to be made, such as theoretical awareness and empirically based knowledge about the students' way of learning, and in this study the injection in the model has been variation theory. In this study the theoretical awareness is analysed via the way the teachers' design the instruction during the process,, which can be questioned. First of all, instruction can be designed based on a more implicit understanding of the students' learning which might not be grounded in a theoretical awareness. Secondly, the impact of the researcher in the process might guide the design based on the theory. However, this could be the case from the first lesson and by that the gradually improvement of increased test scores is difficult to explain. Even if the researcher develops knowledge about the students' expressed awareness of the object of learning during the research lessons, the design of the lessons could have used different patterns of variation in a more developed way from the start although the critical aspects were not yet found. Finally, the tests can be experienced as instrumental and not capturing the ability the research lessons are designed to develop or the increased scores can be an effect of doing the test more than once. What talks against the second objection is the results in research lesson $\mathrm{B}$, where the results were the same at the two test times. And the first objection that the tests do not measure what was supposed to learn, what is said against it, is the increased ability to solve such kind of items for which the teachers have found it difficult to develop students' abilities. What should be of interest to study further is the teachers' way of reasoning during the planning, to separate the effect of the researcher from the teachers' point of view. Another way to study the teachers' theoretical understanding could be to observe some following lessons where the teachers plan and conduct the instruction without collaboration with the researcher. Without such kind of studies, the teachers' development is hard to estimate even if the correlation between the students' increased scores at the tests and the development of the design points at a correlation. In research lesson $\mathrm{C}$, the difference between the results at the pre- and post-test was significant**. However, the aim of this study was to see if the students' test scores increase during the process and if they are significant the purpose has been fulfilled in both cases, even if the study has resulted in other questions raised.

\section{Acknowledgements}

We would like to thank the participating teachers who generously shared their time and teaching and the research team, Learning Design (LeaD), at Kristianstad University for encouragement and support.

\section{References}

Butler, H., Novak Lauscher, S., Jarvis-Selinger, B., \& Beckingham, B. (2004). Collaboration and self-regulation in teachers' professional development. Teaching and Teacher Education, 20, 435-455. http://dx.doi.org/10.1016/j.tate.2004.04.003

Coulter, D. (2002). What counts as action in educational action research? Educational Action Research, 10(2), 189-206. http://dx.doi.org/10.1080/09650790200200181

Day, C., Sammons, P., Hopkins, D., Harris, A., Leithwood, K., Gu, Q., Brown, E., Ahtaridou, E., \& Kington, A. (2009). The Impact of School Leadership on Pupil Outcomes, DCSF Research Report -RR108, London: Department for Children, Schools and Families.

Elliott, J. (2009). Building Educational Theory through Action Research. In S. Noffke, \& B. Somekh (Eds.), The Sage Handbook of Educational Action Research. Los Angeles, London, New Delhi, Singapore and Washington D.C: Sage.

Herr, K., \& Andersson, G. (2005). The action research dissertation: A guide for students and faculty. USA: 
California.

Holmqvist, M., Gustavsson, L., \& Wernberg, A. (2007). Generative learning. Learning beyond the learning situation. Educational Action Research, 15(2), 181-208. http://dx.doi.org/10.1080/09650790701314684

Holmqvist, M., Gustavsson, L., \& Wernberg, A. (2008). Variation Theory - An Organizing Principle to Guide Design Research in Education. In Kelly, A. E., Lesh, R., \& Baek J. (Eds), Handbook of design research methods in education (pp. 111-130). New York: Routledge.

Holmqvist, M. (2011). Teachers' learning in a learning study. Instructional Science, 39(4), 497-511. http://dx.doi.org/10.1007/s11251-010-9138-1

Holmqvist, M., Brante, G., \& Tullgren, C. (2012). Learning Study in Pre-school. Teachers' expectations for children's learning and what they actually learn. The International Journal for Lesson and Learning Studies, 1(2), 153-167. http://dx.doi.org/10.1108/20468251211224190

Lewis, C. (2002). Lesson Study: A handbook of teacher-led instructional change. Philadelphia, PA: Research for better schools, Inc.

Lewis, C., Perry, R., \& Friedkin, S. (2009). Lesson Study as Action Research. In S. Noffke, \& B. Somekh (Eds.), The Sage Handbook of Educational Action Research. Los Angeles, London, New Delhi, Singapore and Washington D.C: Sage.

Magnusson, A., \& Holmqvist, M. (2010). The Rock Cycle - a complex object of learning. In J. V. Carrasquero M. Holmqvist, D. McEachron, A. Tremante, \&. F. Welsch (Eds.), Proceedings. Volume I. The 4th Interntional Multi-Conference on Society, Cybernetics and Informatics. June $29^{\text {th }}-$ July $2^{\text {nd }}, 2010-$ Orlando, Florida, USA. International Institute of informatics and Systemics (pp. 12-17).

Marton, F., \& Booth, S. (1997). Learning and awareness. New Jersey: Lawrence Erlbaum Associates, Publishers.

Morris, A. K., \& Hiebert, J. (2011). Creating shared instructional products: An alternative approach to improving teaching. Educational Researcher, 40(1), 5-14. http://dx.doi.org/10.3102/0013189X10393501

Nuthall, G. (2004). Relating classroom teaching to student learning: A critical analysis of why research has failed to bridge the theory-practice gap. Harvard Educational Review, 74(3), 273-306.

Olteanu, C. (2012). Critical aspect as a means to develop students' learning to simplify rational expressions. Paper presented at the $12^{\text {th }}$ International Congress on Mathematical Education (ICME-12).

Olteanu, C., \& Olteanu, L. (2010). To change teaching practice and students' learningof mathematics. Education Inquiry, 1(4), 381-397.

Runesson, U. (1999). Variationens pedagogik. Skilda sätt att behandla ett matematiskt innehåll. [The Pedagogy of Variation]. Göteborg: Acta Universitatis Gothoburgensis.

Sandoval, W. A., \& Bell, P. (2004). Design-Based Research Methods for Studying Learning in Context: Introduction. Educational Psychologist, 39(4), 199-201. http://dx.doi.org/10.1207/s15326985ep3904_1

The Design-Based Research Collective 2003. Design-based research: An emerging paradigm for educational inquiry. Educational Researcher, 32(1), 5-8. http://dx.doi.org/10.3102/0013189X032001005

Vygotsky, L. (1986). Thought and language. The MIT Press. Cambridge, Massachusetts.

Wells, G. (2009). Dialogic Inquiry as Collaborative Action Research. In S. Noffke \& B. Somekh (Eds.), The Sage Handbook of Educational Action Research, Los Angeles, London, New Delhi, Singapore and Washington D.C: Sage.

Yoshida, M., \& Fernandez, C. (2004). Lesson Study. A Japanese Approach to Improving Mathematics Teaching and Learning. Mahwah: Lawrence Erlbaum Associates Inc. 